\title{
New Bitumens Obtained from Physical Distillation of a Conventional Bitumen Mixed with EVA Copolymer
}

\author{
Goretti Goikoetxeaundia ${ }^{1}$, Alexander Mateos ${ }^{1}$, María Eugenia Muñoz ${ }^{1}$, Anton Santamaría ${ }^{*}, 1$, \\ Inmaculada Martínez ${ }^{2}$ and Pedro Partal ${ }^{2}$ \\ ${ }^{I}$ Polymer Science and Technology Department and Polymer Institute POLYMAT, Faculty of Chemistry, University of the \\ Basque Country UPV/EHU, P.O. Box 1072, E-20080 San Sebastián, Spain \\ ${ }^{2}$ Departament of Chemical Engineering, Faculty of Experiental Science, Campus "El Carmen”, University of Huelva, \\ 21071 Huelva (Spain)
}

\begin{abstract}
Bitumen phases separated from 5\% and 12\% EVA/bitumen blends are investigated. Basic characterization is carried out using a peculiar thin layer chromatographer, the Iatroscan. The rheological and technical analysis lead us to conclude that these macromolecular materials, obtained from physical distillation of the blends, constitute new bitumens of unique properties.
\end{abstract}

Keywords: Blends, Iatroscan, new bitumens, physical distillation, rheology.

\section{INTRODUCTION}

In bitumen/polymer blends the proportion of saturates, aromatics, resins and asphaltenes of the bitumen has a strong influence on the polymer concentration needed to form a polymer network continuous phase. In the particular case of modified bitumen used for roofing, the bitumen/polymer compatibility is described as the capacity of the polymer to absorb a portion of the bitumen constituents to yield an extended polymer matrix. The nature of the polymer and the composition of the bitumen determine the concentration at which a continuous phase is formed. For instance, for Bitu$\mathrm{men} /$ styrene-butadiene-styrene (SBS) blends, it has been claimed that the swelling capacity increases as the bitumen composition passes from saturates to resins and aromatics [1]. On the other hand, in the case of Bitumen /atactic polypropylene (APP) blends, only bitumen having more than $1 / 3$ of asphaltenes+saturated fractions and less than $2 / 3$ of resins+aromatic fraction give enough compatibility to provoke a phase inversion (continuous polymer phase) from 10 to $13 \%$ of polymer [2].

A technical requirement of polymer modified waterproofing membranes is that the selected polymer must combine homogeneously with bitumen, to achieve a morphological structure in which the polymer prevails, with the minimum polymer content as possible. In the case of industrially available Bitumen/SBS membranes polymer rich phase is constituted with less than 15\% SBS. Traditionally the most successful polymer systems for modifying bitumen for roofing purposes are SBS and APP. Fluorescent microscopy,

*Address correspondence to this author at the Polymer Science and Technology Department and Polymer Institute POLYMAT, Faculty of Chemistry, University of the Basque Country, San Sebastian, Spain; Tel: +34 943 018184; Fax: +34 943 015270; E-mail: antxon.santamaria@ehu.es differential scanning calorimetry (DSC) and mechanical thermal analysis (DMTA) have been used to investigate bitumen/SBS blends [3-14] and bitumen/APP blends [2, 1314], as well as bitumen mixtures with ABS [15], polystyrene [15], polyethylene [16], polybutadiene [16], polyvinyl chloride [5], chlorinated polyethylene [16], ethylene-propylene diene monomer (EPDM) [5, 17] and isocyanate [18]. The use of ethylene-vinyl acetate (EVA) as a bitumen modifier for membranes has also been reported in the literature [15, 1922]. As for the rest of the aforementioned polymer systems, the observed EVA swelling is a consequence of the physical distillation derived from the interaction of the polymer matrix with saturate oils. The concept of physical distillation was applied to polymer modified bitumens by Lesuer et al [12]. Notwithstanding the role played by polymer swelling in the required physical properties of waterproofing membranes, not many papers deal with the task of measuring the relative proportion of bitumen to polymer phase after mixing process is achieved. The most employed method of measuring the dispersed phase volume fraction of the blend is image analysis of UV-fluorescence microscopy photographs $[2,11-$ $16,20,22]$.

An interesting collateral derivation of the study of bitumen/polymer mixtures for waterproofing membranes lies on the possibility of obtaining the bitumen phase of the blend, which is separated from the mixture by thermal destabilization. There is certainly a shortage of information on the characterization and properties of the bitumen phase obtained by physical distillation.

In this paper we present novel results on the use of a thin layer chromatography technique, the Iatroscan, to evaluate the actual volume fraction of the components of Bitumen/EVA blends and to determine the composition of the corresponding bitumen phases of the blends. The latter con- 
stitute actually new bitumens of distinguishing rheological and technical features which are investigated.

\section{MATERIALS AND METHODOLOGY}

The blends were based on a 150/200 penetration grade bitumen provided by Cepsa (Spain) and a ethylene-vinyl acetate (EVA) copolymer of 5\% Vinyl acetate, $0.7 \%$ Carbon black and 33\% Crystallinity.

Bitumen/polymer blends were prepared by mechanical stirring in a lab-scale reactor using an Ika Labortechnik MF 10 mixer with a four blade impeller. The polymer was added to the bitumen and mixing was maintained at $180^{\circ} \mathrm{C}$ and 600 r.p.m. for 2 hours.

The morphology of the bitumen/polymer blends was studied in a Leitz Aristomet optical microscope.

A relatively recent technology, firstly applied by Suzuki [23] and known as Iatroscan, combines thin-layer chromatography (TLC) with flame ionization detection. This technique has been successfully employed to analyze saturate, aromatic, resin and asphaltene (SARA) fractions of crude oils and we remit to literature $[1,2,24,25]$ for further explanations. In our case, the SARA fractions of the bitumen were separated and quantified using selective solvents like hexane, toluene and a 95\%-5\% mixture of dicloromethane/methanol. The corresponding bituminous phase of each blend was also analysed using this technique. The bituminous phase was separated from the blend by gravity in a cylinder chamber of radius $\mathrm{R}=1.7 \mathrm{~cm}$ at $\mathrm{T}=165^{\circ} \mathrm{C}$, under the conditions established in UNE-EN 13399 Spanish test.

Small amplitude oscillatory flow measurements in the linear regime were carried out in plate-plate mode (diameter $4 \mathrm{~cm}$ ) in a stress-controlled TA Instrument AR-G2.

Technical characteristics of the original and new bitumens (bituminous phase of each blend) were determined following ASTM standards.

Original bitumen measurements were made with samples submitted to the same thermo-mechanical treatment as the blend.

\section{RESULTS AND DISCUSSION}

\section{Iatroscan Analysis of New Bitumens Obtained by Physi- cal Distillation}

In the initial part of the mixing process a well dispersed phase of polymer droplets is formed, but due to physical distillation the droplets swell (typically to $15-40 \mu \mathrm{m}$ diameter), increasing its volume with absorbed maltenic fractions of the bitumen. In Fig. (1) the rheological and morphological evolution of the mixture during the blending process is presented. As can be seen with the sequential photographs of the process, good dispersion of the polymer (white droplets) in the bitumen matrix (dark) requires a low torque, but the subsequent swelling of the droplets provokes a rapid torque increase. At the end of the mixing process a co-continuous morphology is observed. This is a significant result, since the initial composition contains only $12 \%$ EVA by weight. To evaluate the swelling or physical distillation effect associated to the interaction of the different constituents of bitumen with the polymer, the Iatroscan technique is used. The bitumen phase is separated from the blend using the thermal destabilizing procedure described in the experimental part. The respective chromatograms of pure bitumen and bitumen phases separated from 5\% and 12\% EVA blends are presented in Fig. (2). The corresponding intensities of the signals of saturates, aromatics, resins and asphaltenes vary according with the degree of their interactions with EVA. This allows determining the percent of each component in pure bitumen and in the bitumen phases of the blends, leading to establish the percent of bitumen and the percent of polymer rich phase. The results are shown in Table $\mathbf{1}$.

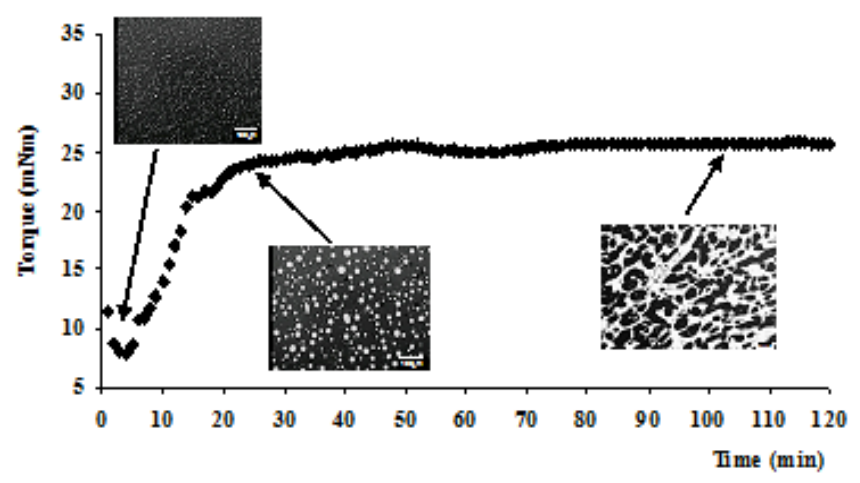

Fig. (1). Torque variation and morphological evolution of a bitumen/EVA mixture (12\% EVA by weight) during the blending process.

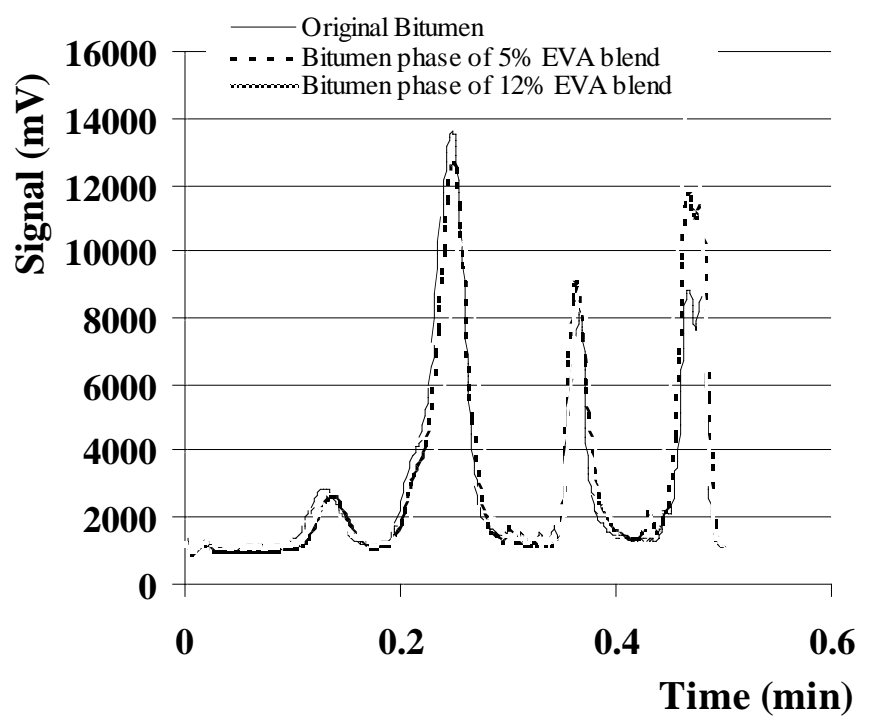

Fig. (2). Iatroscan chromatograms of pure bitumen and bitumen phases separated from 5\% and 12\% EVA blends.

As a result of the physical distillation process, a $5 \%$ by weight EVA, leads to a $25 \%$ dispersed phase and a $12 \%$ EVA leads to a $43 \%$ phase. This justifies the microscopy morphological analysis, in particular the co-continuous morphology observed in Fig. (1) when the initial 12\% EVA passes to a swollen $43 \%$ phase during the mixing process. The bitumen phases of 5\% and 12\% EVA blends constitute actually new bitumens (bitumens of different composition), obtained as a result of the interaction between the copolymer and the bitumen. The composition of the bitumen phases of 
Table 1. Composition of the Original Bitumen and Bitumen Phases of 5\% and 12\% EVA Blends, According to Iatroscan Results. In the Second Column the Data are Normalized to Asphaltene Content Since EVA does Not Interact with this Component. Comparing the Normalized Values of the Components, Bitumen and EVA Fractional Weight Values of the Blends are Deduced (See Text). The Colloidal Index is Defined as C.I.= (Aromatics+Resins)/(Saturates+Asphaltenes)

\begin{tabular}{|c|c|c|c|c|}
\hline & Composition (\%) & Normalized Composition & EVA Fractional Weight of the Blend & Colloidal Index \\
\hline Original Bitumen & $\begin{array}{c}\text { Saturates: } 6.5 \\
\text { Aromatics: } 53.3 \\
\text { Resins: } 15.1 \\
\text { Asphaltenes: } 25.1\end{array}$ & $\begin{array}{c}\text { Saturates: } 0.26 \\
\text { Aromatics: } 2.12 \\
\text { Resins: } 0.60 \\
\text { Asphaltenes: } 1\end{array}$ & & 2.12 \\
\hline Bitumen phase of $5 \%$ EVA blend & $\begin{array}{c}\text { Saturates: } 5 \\
\text { Aromatics: } 43.8 \\
\text { Resins: } 19.3 \\
\text { Asphaltenes: } 31.9\end{array}$ & $\begin{array}{c}\text { Saturates: } 0.16 \\
\text { Aromatics: } 1.37 \\
\text { Resins: } 0.60 \\
\text { Asphaltenes: } 1\end{array}$ & 0.25 & 1.7 \\
\hline Bitumen phase of $12 \%$ EVA blend & $\begin{array}{c}\text { Saturates: } 3.6 \\
\text { Aromatics: } 36 \\
\text { Resins: } 18.9 \\
\text { Asphaltenes: } 41.5\end{array}$ & $\begin{array}{c}\text { Saturates: } 0.09 \\
\text { Aromatics: } 0.87 \\
\text { Resins: } 0.45 \\
\text { Asphaltenes: } 1\end{array}$ & 0.43 & 1.21 \\
\hline
\end{tabular}

$5 \%$ and $12 \%$ EVA blends are shown in Table 1 . The results are fixed by the chemical affinity between EVA and bitumen, which is given by the proximity of the solubility parameter of the copolymer to the corresponding solubility parameters of the different components of the bitumen. As can be seen in Table 2 , the solubility parameter of EVA lies close to the solubility parameters of aromatics and saturates, which justifies the predisposition of the copolymer to absorb these bitumen components in the mixing process. Consequently the percentage of saturates and aromatics is considerably lower for the bitumen obtained after physical distillation with EVA (bitumen phase of the blend) than for pure bitumen.

Table 2. Solubility Parameters of EVA Copolymer and the Components of Bitumen

\begin{tabular}{|c|c|}
\hline $\begin{array}{c}\text { Copolymer and Components of } \\
\text { Bitumen }\end{array}$ & $\begin{array}{c}\text { Solubility Parameters } \\
\text { (MPa) })^{\mathbf{0 . 5}}\end{array}$ \\
\hline \hline Ethylene-vinyl acetate (EVA) & $17.7-19.5$ \\
\hline Saturates & $17.4-20.0$ \\
\hline Aromatics & $19.0-22.5$ \\
\hline Resins & $21.9-26.6$ \\
\hline Asphaltenes & $25.0-33.0$ \\
\hline
\end{tabular}

On the other hand, as could be expected taking into account the disparity of both solubility parameters of resins and asphaltenes as compared to EVA, these components do not interact at all with the copolymer. This is in particular reflected in the increase of the percentage of asphaltene observed in the bitumen phase of the blends (Table 1). In brief, the new bitumens obtained from physical distillation and subsequent thermal destabilization can be well characterized using Iatroscan analysis. In the continuation, rheological and technical features of these new bitumens are presented.
Thermorheological Behaviour: Frequency-Temperature Superposition

Time-temperature or frequency-temperature superposition of viscoelastic data is considered a valuable tool for the analysis of polymers, because the results can be associated with the molecular and structural implications of the different relaxation modes involved in the system. During last decade we have chosen double logarithmic plots of phase angle $\delta$ versus complex modulus $G^{*}$ (the so called Black diagrams or Mavridis-Shroff plots [26]) to investigate the thermorheological complexity (breakup of frequencytemperature superposition) of some polymers [27-29]. Moreover, the failure of frequency-temperature superposition in dynamic viscoelastic results of bitumen has also been demonstrated using this rheological technique [12, 25, 30, 31]. This is not surprising considering the complexity of bitumen and the fact that measurements were carried out in a range of temperatures (from -20 to $70^{\circ} \mathrm{C}$ ) which includes the glass transition temperatures of maltenes and asphaltenes. To avoid the effect of these relaxations, in our case we contemplate the plots of phase angle $\delta$ versus complex modulus $\mathrm{G}^{*}$ of the different bitumens in the range of temperatures 90$180^{\circ} \mathrm{C}$.

The results, shown in Fig. (3), are correlated to the composition of the investigated bitumens which is given in terms of the Colloidal Index, defined as C.I. = (aromatics+resins)/(saturates+asphaltenes). 70 years after its definition [32-33] this index remains as a sound relationship to express the association degree of asphaltenes. It is currently admitted that the asphaltenes are more peptized by the resins as the Colloidal Index augments. AFM and SEM analysis carried out by Loeber et al. [25] shows that a bitumen with a low C.I. has a connected network structure, whereas individual domains of asphaltene particles form the structure of a bitumen of a high Colloidal Index. This conclusive remark is compatible with the results of Fig. (3), which show that the thermorheological complexity is reduced as the colloidal 
index of the bitumen decreases. The level of thermorheological complexity is given by the corresponding critical $\mathrm{Gc}^{*}$ values at which the data deviate from a reference curve taken at $90^{\circ} \mathrm{C}$. This allows defining the relaxation times associated to this deviation as $\tau=1 / \omega_{c}$, where $\omega_{c}$ is the frequency at $\mathrm{G}^{*}=\mathrm{Gc}^{*}$. At sufficiently low frequencies all the samples display a viscous $\left(\delta=90^{\circ}\right)$ thermorheologically simple behaviour, but as frequency increases thermorheological complexity appears. This reflects the response of individual domains of asphaltene particles possessing a characteristic relaxation time. That is to say, as frequency increases more local motions, involving shorter times, can be detected. The particular behaviour observed at a certain temperature reflects the dynamics of asphaltene domains which have relaxation times shorter than the corresponding $\tau=1 / \omega_{\mathrm{c}}$ values shown in Fig. (3). For the original bitumen, which has the highest Colloidal Index (C.I.=2.12), three different relaxation times corresponding to 120,150 and $180^{\circ} \mathrm{C}$, are noticed (Fig. 3a). But as the Colloidal Index decreases the number of detected relaxation times lessens, as seen in Fig. (3b) and (3c). Actually for the lowest Colloidal Index bitumen (bitumen phase of $12 \%$ EVA blend, with C.I.=1.21) a thermorheologically simple response can be claimed in the range $90-150^{\circ} \mathrm{C}$. No individual domains are detected, unless experiments at $180^{\circ} \mathrm{C}$ involving times shorter than $\tau=0.0625 \mathrm{~s}$ or frequencies larger than $\omega_{\mathrm{c}}=16 \mathrm{rad} / \mathrm{s}$ (which corresponds to $\mathrm{Gc}^{*}=10$ $\mathrm{Pa}$ in Fig. (3c)), are carried out. Therefore, the thermorheological complexity analysed by Mavridis-Shroff plots or Black diagrams offers a route to disclose in which bitumens asphaltenes are more peptized in the oil based medium. The perfectly connected network structure that according to the studies of Loebler et al. [25] appears for very low Colloidal Index bitumens, is reflected by a thermorheologically simple behaviour.

\section{Viscosity and Technical Characteristics}

The real part $\eta^{\prime}=G^{\prime \prime} / \omega$ of the complex viscosity $\eta^{*}$ at $90^{\circ} \mathrm{C}$ is presented in Fig. (4) for the original and new bitumens

The data are fitted to the Briedis and Faitelson model [34]:

$\eta^{\prime}=\frac{\eta_{0}}{1+(\omega \lambda)^{\alpha}}$

where $\eta_{0}$ is the linear or Newtonian viscosity, $\lambda$ the relaxation time and $\alpha$ the non-linearity index. The values of the fitting parameters for the different samples are presented in Table 3.

The variation of the Newtonian viscosity with temperature is fitted to an Arrhenius like equation $\eta_{0} \propto \exp E_{a} / R T$, where $\mathrm{R}$ is the gas constant and Ea is the activation energy of flow. The values of the latter are included in Table $\mathbf{3}$.

The linear Newtonian viscosity at $90^{\circ} \mathrm{C}$ augments from $\eta_{0}=5$ Pa.s for original bitumen to $\eta_{0}=53$ Pa.s for the bitumen phase of 5\% EVA blend and $\eta_{0}=1620$ Pa.s for the bitumen phase of $12 \%$ EVA blend. These enormous differences are (a) Original Bitumen (Colloidal Index C.I = 2.12)

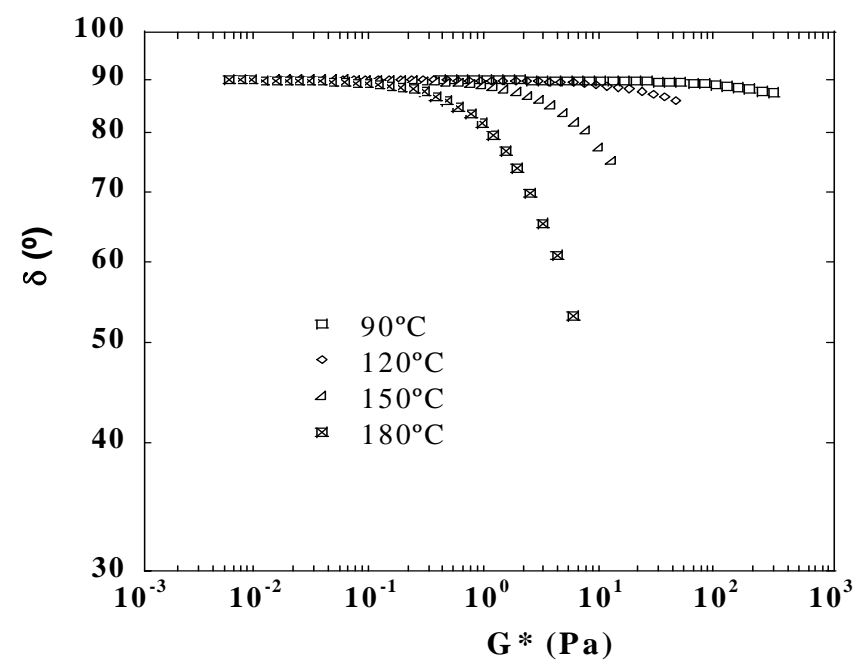

(b) Bitumen phase separated from 5\% EVA blend (Colloidal Index C.I $=1.7)$.

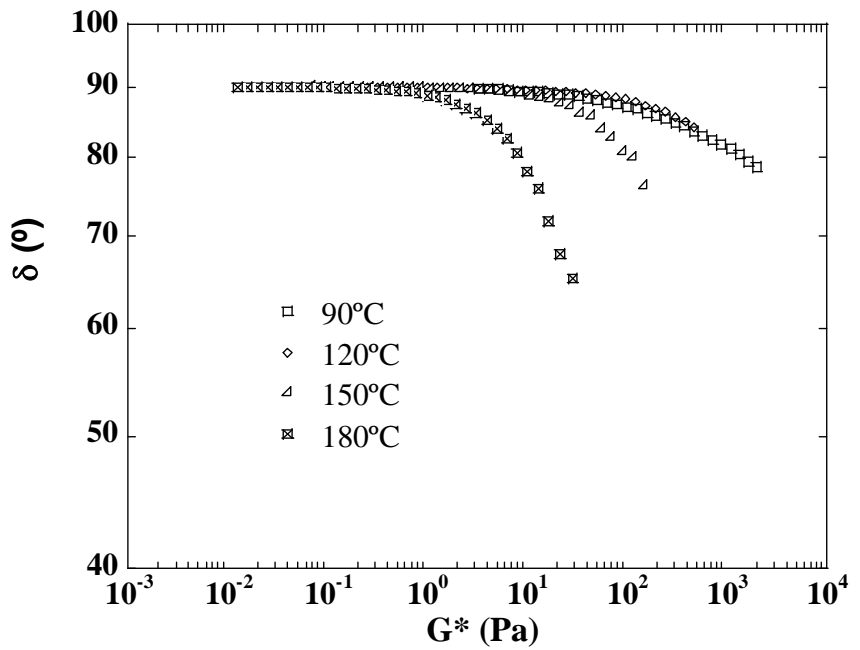

(c) Bitumen Phase Separated from 12\% EVA Blend (Colloidal

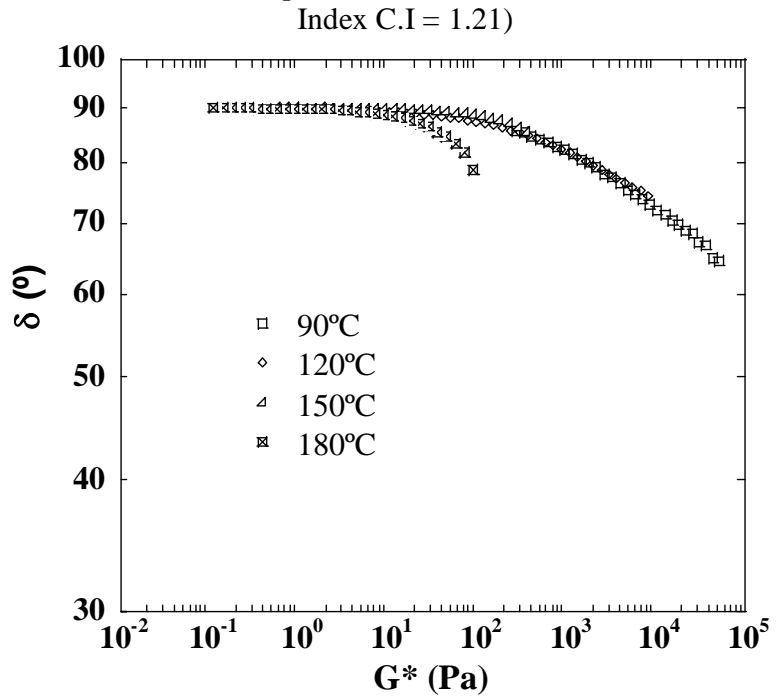

Fig. (3). Plots of phase angle $\delta$ versus complex modulus $G^{*}$ for the different bitumens in the range of temperatures $90-180^{\circ} \mathrm{C}$. The level of thermorheological complexity is correlated with the indicated Colloidal Index values (see text). a) Original bitumen b) Bitumen phase separated from 5\% EVA blend c) Bitumen phase separated from $12 \%$ EVA blend. 
reduced as temperature increases, because the activation energy of flow Ea grows from $24 \mathrm{~kJ} /$ mole for original bitumen to $74 \mathrm{~kJ} / \mathrm{mole}$ for the bitumen phase of $5 \%$ EVA blend and $119 \mathrm{~kJ} / \mathrm{mole}$ for the bitumen phase of $12 \%$ EVA blend. We estimate that the observed viscosity enhancement is associated with the very dense network structure envisaged for the new bitumens obtained from physical distillation of the blends.

Table 3. Parameters of the Briedis and Faitelson Model (Eq. 1) and Flow Activation Energy Ea Values for Original and Bitumen Phases of 5\% and 12\% EVA Blends

\begin{tabular}{|c|c|c|c|c|}
\hline & $\eta_{0}$ (Pa.s) & $\lambda(\mathbf{s})$ & $\boldsymbol{\alpha}$ & $\mathbf{E a}(\mathbf{k J} / \mathbf{m o l e})$ \\
\hline \hline Original Bitumen & 5 & 0 & 0.9 & 24 \\
\hline Bitumen phase of 5\% EVA blend & 53 & 0.01 & 0.5 & 74 \\
\hline Bitumen phase of 12\% EVA blend & 1620 & 0.52 & 0.4 & 119 \\
\hline
\end{tabular}

On the other hand, the viscosity results point out that the technical characteristics of the new bitumens should be completely different to those of the initially considered bitumen. Softening point temperature obtained by Ring and Ball tests and Penetration Grade values are presented in Table 4.

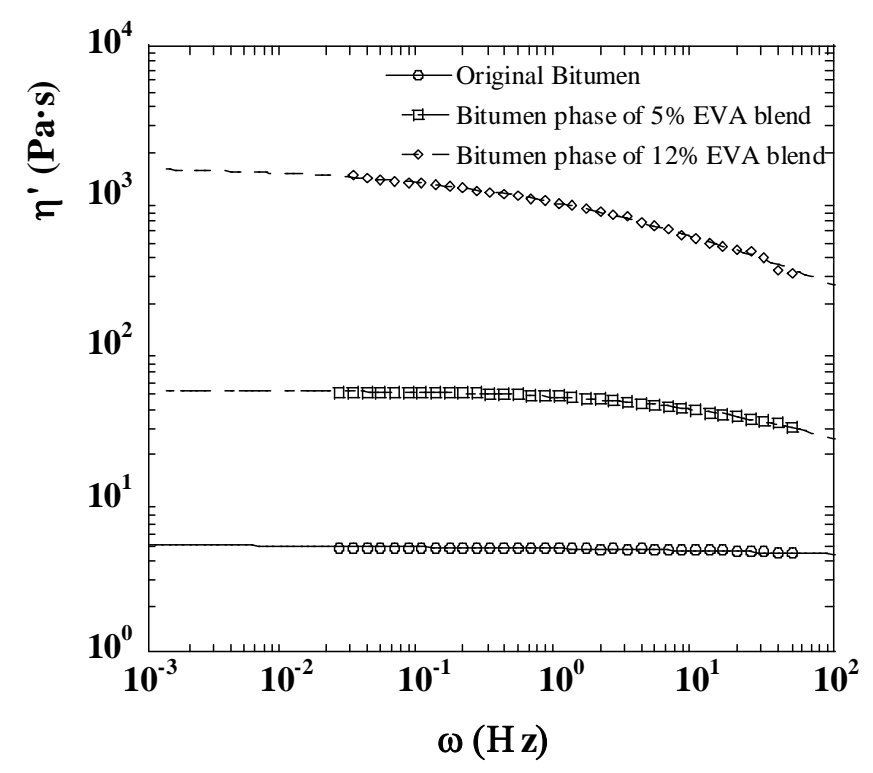

Fig. (4). The real part $\eta^{\prime}$ of the complex viscosity as a function of frequency at $90^{\circ} \mathrm{C}$ for the original bitumen and the bitumen phases of $5 \%$ and $12 \%$ EVA blends. The data are fitted to the Briedis and Faitelson model (Eq. 1).

\section{CONCLUSIONS}

Bitumen phases separated from 5\% and 12\% EVA/bitumen blends using a thermal destabilizing procedure constitute new bitumens with some peculiar features.

Table 4. Technical Characteristics of the Original Bitumen and Bitumen Phases of 5\% and 12\% EVA Blends. Aromatic/Asphaltene Ratio is Obtained from Table I. The Penetration Grade of the Bitumen Before Submitting the Sample to the Same Thermomechanical History as Bitumen/Polymer Blends (See Experimental) is $150 \mathrm{dmm}$

\begin{tabular}{|c|c|c|c|}
\hline & $\mathbf{T}_{\text {R\&B }}\left({ }^{\circ} \mathbf{C}\right)$ ASTM-D36 & Penetration Grade (dmm) ASTM-D5 & Aromatic/Asphaltene \\
\hline \hline Original Bitumen & 47 & $100.3 \pm 1.2$ & 2.12 \\
\hline Bitumen phase of 5\% EVA blend & 62 & $28.6 \pm 1.3$ & 1.37 \\
\hline Bitumen phase of 12\% EVA blend & 80 & $9.2 \pm 0.4$ & 0.86 \\
\hline
\end{tabular}

New bitumens are much harder (lower penetration grade) than the original bitumen. Actually, a penetration degree below $10 \mathrm{dmm}$, as such offered by the bitumen phase of $12 \%$ EVA blend, is out of the range of known bitumens, whatever is their origin. Although establishing a sound correlation between bitumen composition and penetration grade is not an easy task, we remark that our samples follow the trend reported by Loeber et al. [25] for a series of standard bitumens from different origins: the penetration degree of the bitumen decreases as the aromatic/asphaltene ratio diminishes (Table 4).

The photograph (Fig. 5) shows the results of the physical distillation process of $88 \%$ Bitumen-12\% EVA blend. The lower part constitutes a new bitumen of unique properties
The composition of the new bitumens is determined employing a thin layer chromatographer, the Iatroscan. The association degree of asphaltenes is given by the Colloidal Index, C.I., which in turn is correlated with frequencytemperature thermorheological results: the higher C.I. is, most noticeable becomes thermorheological complexity. The bitumen phase separated from 12\% EVA blend displays a huge viscosity compared to original bitumen, which is compatible with a dense network and a very low penetration grade $(9.2 \mathrm{dmm})$. Actually, such a low grade is out of the range reported for conventional bitumens. Therefore, physical distillation opens a route to produce new bitumens of technical characteristics distinct from currently known bitumens. 


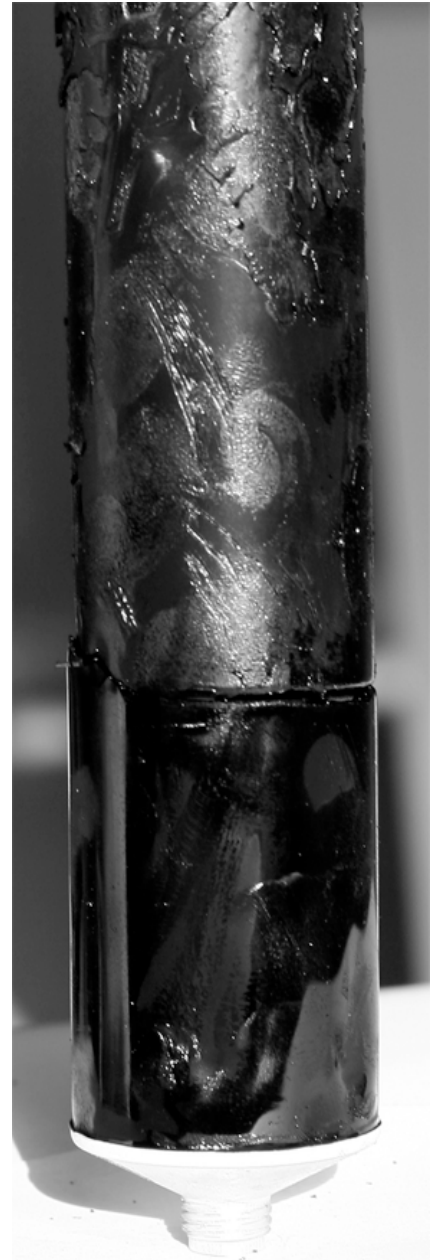

Fig. (5). Photograph of the blend after physical distillation.

\section{ACKNOWLEDGMENTS}

Financial support through MEC (MAT2004-06299-C0201) (Spanish Government) and (GIC07/135-IT-284-07) (Basque Government) is acknowledged.

\section{REFERENCES}

[1] Teugels, W. In Bitumen Parameters affecting Roofing Membrane quality, Proceedings of the National Congress of Waterproofing, Madrid, Spain, June 9-10, 2005; pp. 29-44.

[2] Paolo, I.; Brandolese, E. In Polypropilene-Asphalt Mixtures for Waterproofing Membranes, Proceedings of the Symposium on Modified Asphalts, Orlando, Florida, August 25-30, 1996; pp. 1250-1254.
[3] Farling, M.S. Rubber World, 1988, 197, 20.

[4] Diani, E.; Gargani, L.; Vitalini, L. Rubber World, 1992, $206,44$.

[5] Oba, K.; Björk, F. Polym. Testing, 1993, 12, 35.

[6] Rodríguez, I.; Dutt, O.; Paroli, R. M. ; Mailvaganam, N. P. Mater. Struct., 1993, 26, 355.

[7] Usmani, A. M. Polym. News, 1996, 21, 262.

[8] Wloczysiak, P.; Vidal, A.; Papirer, E.; Gauvin, P. J. Appl. Polym. Sci., 1997, 65, 1595.

[9] Wloczysiak, P.; Vidal, A.; Papirer, E. J. Appl. Polym. Sci., 1997, 65, 1609 .

[10] Soenen, H.; Sandman, B.; Nilsson, A. In Rheologycal and Chemical Evaluation of the Ageing of SBS Modified Bitumen as used in Roofing, Proceedings of the XIth International waterproofing and roofing congress, Florence, Italy, October $2-4,2000$; pp. $24-46$.

[11] Fawcett, A. H.; McNally, T. Colloid Polym. Sci., 2003, 281, 203.

[12] Lesueur, D.; Gérard, J. F.; Claudy, P.; Létoffé, J. M.; Martin, D. Planche, J. P. J. Rheol., 1998, 42, 1059.

[13] Fawcett, A. H.; McNally, T.; McNally, G. J. Elast. Plast., 1999, 31 , 334.

[14] Fawcett, A. H.; McNally, T. Polymer, 2000, 41, 5315

[15] Fawcett, A. H.; McNally, T. Polym. Eng. Sci., 2001, 41, 1251.

[16] Fawcett, A. H.; McNally, T.; McNally, G. Adv. Polym. Tech., 2002, $21,275$.

[17] Paroli, R. M.; Dutt, O.; Delgado, A. H.; Mech, M. N. Thermo Acta, 1991, 182, 303.

[18] Singh, B.; Tarannum, H.; Gupta, M. J. Appl. Polym. Sci., 2003, 90, 1365.

[19] Fawcett, A. H.; McNally, T.; McNally, G. Polym. Prepr. (Am. Chem. Soc., Div. Polym. Chem.) 1999, 40, 216.

[20] Fawcett, A. H.; McNally, T.; Macromol. Mater. Eng., 2001, 286 , 126.

[21] Goikoetxeaundia, G.; González, O.; Muñoz, M.E.; Peña, J.J.; Santamaría, A. Macromol. Mater. Eng., 2007, 292,715.

[22] Airey, G.D. Construction and Building Materials, 2002, 16, 473.

[23] Suzuki, Y. "2 $1^{\text {st }}$ Annual Meeting of Japan Society for Analytical Chemistry", 1972, 47.

[24] Fan, T.; Buckley, J.S. Energy Fuels, 2002, 161571

[25] Loeber, L.; Muller, G.; Morel, J.; Sutton, O. Fuel, 1998, 77, 1443.

[26] Mavridis, H.; Shorff, R. N. Polym. Eng. Sci., 1992, 32, 1778.

[27] Zárraga, A.; Peña, J. J.; Muñoz, M.E.; Santamaría, A. J. Polym. Sci. Polym. Phys., 2000, 38, 469

[28] Rojo, E.; Peña, B.; Muñoz, M.E.; Santamaría, A. Macromol. Chem. Phys., 2006, 207, 1781.

[29] Vega, J. F.; Fernandez, M.; Santamaría, A.; Muñoz-Escalona, A.; Lafuente, P. Macromol. Chem. Phys., 1999, 200, 2257.

[30] Lesueur, D.; Gerard, J.; Claudy, P.; Létoffé, J. J. Rheol., 1996, 40, 813.

[31] González, O.; Peña, J. J.; Muñoz, M. E.; Santamaría, A.; PérezLepe, A.; Martínez-Boza, F.; Gallegos, C. Energy Fuels, 2002, 16, 1256.

[32] Pfeiffer, J. P.; Van Doormaal, P. M. J. Inst. Petrol. Technol., 1936, 22, 414.

[33] Pfeiffer, J. P.; Saal, R. N. J. Phys. Chem., 1940, 44, 139.

[34] Vinogradov, G. V.;. Malkin, A. Y. Rheology of polymers, Ed.; Mir Publishers, Moscú 1980

(C) Goikoetxeaundia et al.; Licensee Bentham Open.

This is an open access article licensed under the terms of the Creative Commons Attribution Non-Commercial License (http://creativecommons.org/licenses/bync/3.0/)/ which permits unrestricted, non-commercial use, distribution and reproduction in any medium, provided the work is properly cited. 